\title{
Postmodern trends in the development of creolized safety instructions for air passengers: didactic aspects
}

\author{
Olga Fedotova ${ }^{1, *}$ and $V$. Latun ${ }^{2}$ \\ ${ }^{1}$ Don State Technical University, 1 Gagarin sq., Rostov on Don, 344003, Russia \\ ${ }^{2}$ Southern Federal University, B. Sadovaya Str., 105/42, Rostov on Don, 344006, Russia
}

\begin{abstract}
The article discusses approaches to the creation of non-standard training tools - safety instructions for passengers of various Russian airlines. It is shown that all the requirements of the regulatory documents of international and regional security organizations are formally observed. However, due to the great competition between airlines, they use different concepts for presenting educational information. A number of airlines use postmodern reporting approaches that question the educational effect of the safety instruction.
\end{abstract}

\section{Introduction}

The problems of ensuring the safety of passengers on board civil aircraft are the object of increased attention of developers of new aircraft and helicopters, operational services that ensure flight safety and their training, as well as members of flight and on-board crews. The development of civil aviation in the twentieth century has led to the need for legislative regulation of the safety of international flights based on the development of international standards and regulations. Their implementation is necessary to ensure the efficiency of air traffic. The most important documents of a regulatory and legal nature are instructions for participants in air traffic of various typological groups. The approved instructions have the status of a legal document issued for the purpose of establishing rules and regulations. They regulate organizational, scientific, technical, technological and other special aspects of the activities of organizations and citizens.

In Russia, the first instruction containing technical regulations in the form of a description of technical operations for the manufacture of fireworks was compiled in 1777 by gunner Mikhail Danilov. This instruction already contains a requirement to comply with safety measures when starting fireworks. According to the style of presentation of information, this instruction is instructive in nature. It is aimed at determining the order of actions that minimize possible negative consequences for viewers. The tradition of creating instructional training materials for employees and customers is currently preserved. They are binding.

\footnotetext{
${ }^{*}$ Corresponding author: fod1953@yandex.ru
} 
In the area of aviation security, instructions are developed by various airlines in in competition with each other. When developing modern instructions for passengers, their authors use various marketing strategies. One of the strategy tools is the original presentation of mandatory information for passengers. The methods used for presenting information, on the one hand, are designed to convey to the passenger the content required for familiarization. On the other hand, the safety instruction is a reflection of the style differences of the era embodied in the obligatory content and sequence of the information units.

\section{Methodology and methods}

The purpose of this article is to define the features of the modern marketing strategy used by airlines to inform about safety measures during flight and to maintain the attention of passengers in the context of the world perception of the era.

The empirical source of the study is 1) documents regulating the observance of safety measures on board civil aircraft and 2) passengers briefing cards of Russian airlines (Azimuth.aero, S7, Aeroflot and Red Wings).

Research methods - mainly theoretical methods: various types of analysis, comparison, analogy, interpretation.

The study was conducted in two stages.

\section{Results and discussion}

The objective of the first stage of the study was to establish the degree of compliance of passengers briefing cards of different countries with the regulatory requirements in the field of security of international organizations and national civil aviation authorities. Based on the study of a wide range of sources, it was found that civil air carriers are guided by uniform rules of professional activity. These regulations are developed by the United Nations Intergovernmental Specialized Agency, established in 1944 to ensure the orderly and regulated functioning and development of the world air transport system - ICAO International Civil Aviation Organization.

ICAO is intensively working on the development and implementation of regulatory documents on the regulation of international civil aviation in the field of flight safety, aviation security. This also includes the following issues: protection from acts of unlawful interference, air transport, environmental protection from the effects of aviation, air law. Legal documents are subject to strict application.

The most important of them is: Convention on International Civil Aviation - Doc 7300 [1], which is supplemented by 19 Appendices. Appendix 6 is devoted to the problems of aircraft operation. It defines in detail the conditions of flight operations, aircraft equipment, flight documentation. At the same time, these issues were considered not only with the position of training the crew and ground services, but also passengers, who must be informed about the rules of conduct on board the aircraft, including in emergency situations.

The Global Aviation Safety Plan is currently in force. 2020-2022. Doc 10004 [2], which came into force after the expiration of a similar document in 2017 - 2019. Issues related to ensuring the life of passengers on board are the topic of scientific discourse not only by experts in the field of flight safety [3-6], but also by authors whose attention is paid to the pastime of passengers on board the aircraft during the flight [7-9].

As noted in the regulatory documents, passengers should be given the opportunity to familiarize themselves with the rules of conduct on board the aircraft before and during the 
flight. Many airlines use safety training demonstrations that show the algorithm of behavior in a regular and extreme situation. Security demonstrations (or "live briefing") are carried out by stewards. On many large aircraft equipped with in-flight entertainment tools, safety demonstrations can take place in the form of videos lasting from two to six minutes.

The general rule in force according to the international regulations is the presence of passengers briefing card - an instruction informing passengers about the rules of conduct. A card with a safety instruction in the pocket of the seat in front of the passenger is a mandatory element, the presence of which is checked during the pre-departure check. The instructions were introduced in 1978 as a mandatory means of information [10, 11]. However, in Russia, Passenger Notes were introduced back in 1960. Among the foreign developers of the passengers briefing card, the oldest company Interaction Research Corporation [12] should be named, which has extensive experience in creating training products of this type.

Instructions developed and published by this firm and other manufacturers must reflect the basic positions provided in Appendix 6. The Russian State Civil Aviation Service has developed "Technical Requirements for Safety Instructions for Passengers of Civil Aviation Aircraft" [13], which is guided by Russian airlines.

The objective of the second stage of the study was to identify the qualitative originality of approaches to creating a creolized text of instructions for passengers as educational material. The drafters of the instructions should focus the attention of passengers on the need to familiarize themselves with the content of the text presented on the card. Therefore, all instructions begin with a proposal to carefully read and assimilate the text.

At the same time, airlines that have a long experience in the market of civil passenger services, do not place images with the image of a flight attendant on the instructions. New or rebranded airlines pay significant attention to this issue (Figure 1).

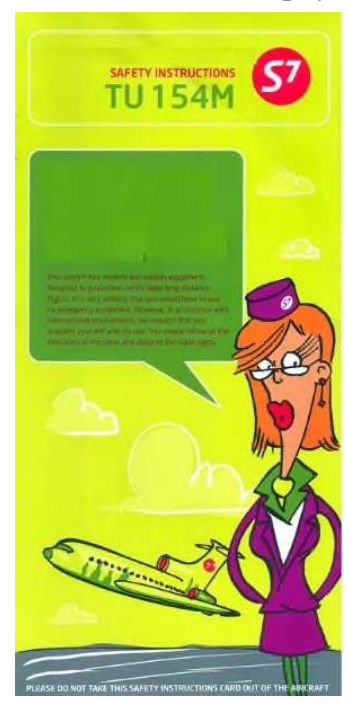

$\mathbf{a}$

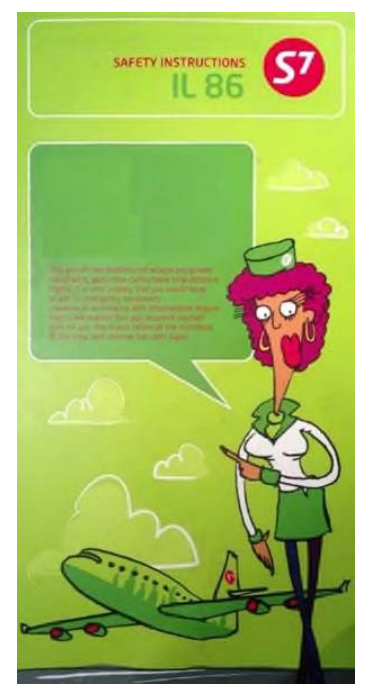

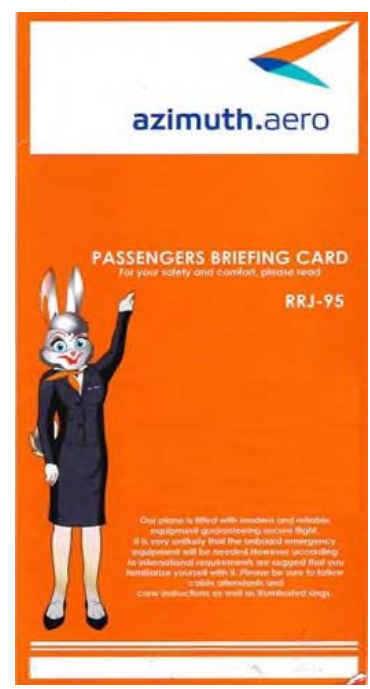

b

Fig. 1. Requesting passengers to read the content of the safety instructions: a - S7, b-Azimuth.aero.

In Figure 1a, it can be noted that the authors of the document use postmodern stylistics to attract attention: the flight attendant's speech is enclosed in a speech balloon [14, 15] used when creating comics; the natural proportions of the body are not observed; there are moments of shocking and self-irony. There is a discrepancy between the service uniform and accessories (large evening earrings). The face has exaggerated lips, eyelashes and eyes, which creates a playful and ambiguous image of the character. 
Figure $1 \mathrm{~B}$ reflects the postmodern tendency to anthropomorphism, when the physical and mental properties of animals are transferred to humans. Depicting the stewardess in the guise of a hare, the compilers of the safety instructions endow her with such character traits - gentleness, sensitivity, caution, quick wit.

According to the technical requirements for the preparation of instructions [13], it must necessarily reflect the necessary actions of passengers and crew in an emergency. At the same time, new and rebranding airlines, unlike those that have conquered the market, are trying to draw attention to safety problems using original techniques for portraying the situation. As follows from the text of the instruction, images of a fixed pose during an emergency landing, the ability to put on an oxygen mask and go down an inflatable ladder, refusal to take out excess luggage, etc. are mandatory. The Figures 2- 5 show training illustrations that reflect these actions on the instructions of various airlines.

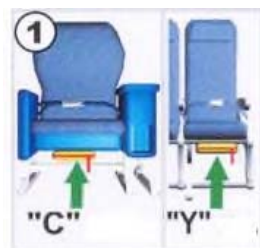

(5)

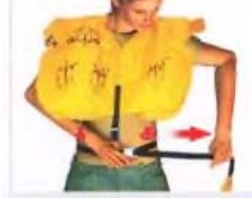

(2)
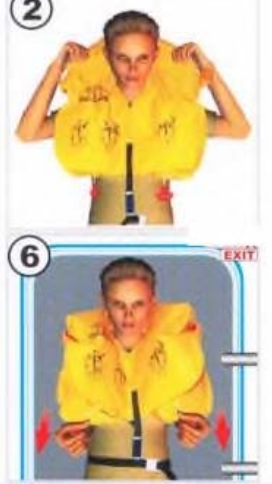

(3)

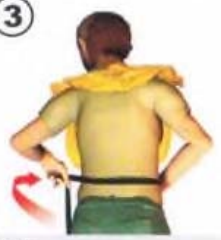

(7)

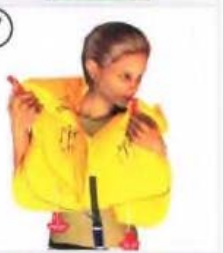

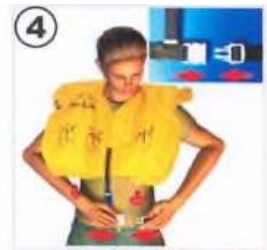

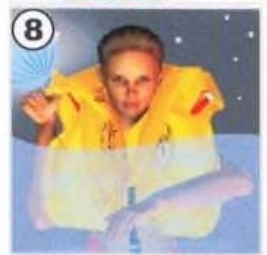

a

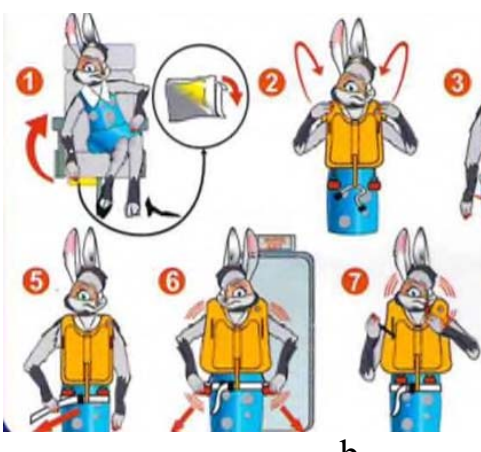

$\mathrm{b}$
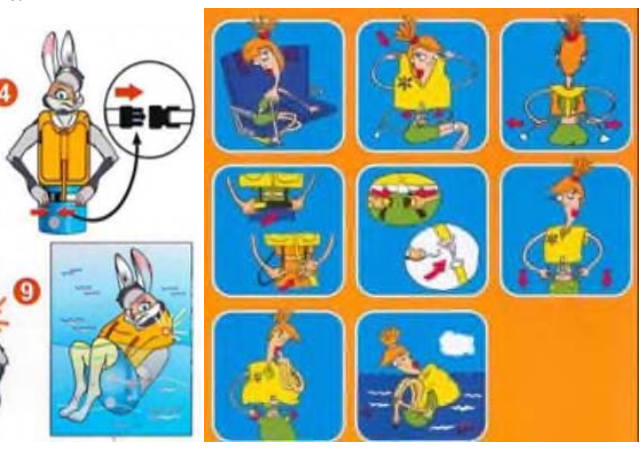

$\mathrm{c}$

Fig. 2. Training illustrations that reflect these actions on the instructions of various airlines: a Aeroflot, B - Azimuth.aero, c-S7.

Figure 2 shows that the photographic accuracy of the training procedure for putting on the vest, which must be demonstrated by the flight attendant, is preserved only on the instructions of Aeroflot. The postmodern trend towards anthropomorphism persists in the image on the Azimuth airlines passengers briefing cards. Concept S7 retains an ambiguous image of the flight attendant, giving him playfulness and playfulness, not suitable for an emergency.

Figure 3, 4, 5 shows the information contained in the instructions of Aeroflot, Azimuth, S7 and Red Wings, which are operated by passengers. 

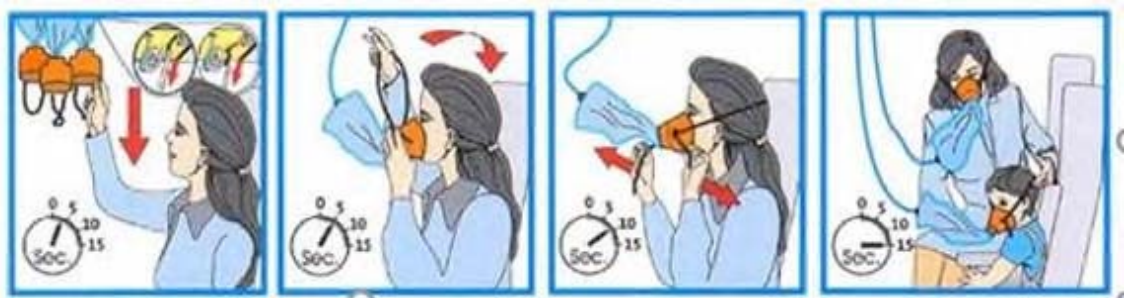

a
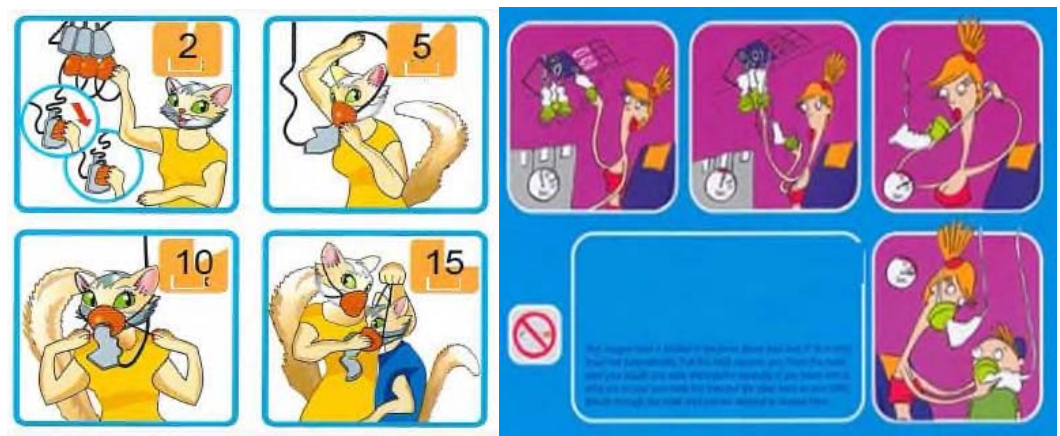

b

Fig. 3. Training in using an oxygen mask: a - Aeroflot, $\mathrm{B}-$ Azimuth.aero, $\mathrm{c}-\mathrm{S} 7$.

The style of the images, which reflects the concept of the training process for putting on an oxygen mask, remains the same. A simple and clear image of the four-step procedure can be found in the instructions for passengers from Aeroflot. Azimuth.aero remains true to the anthropomorphic image concept. S7 does not abandon the parody approach.

The same trend persists in the image of other aspects related to passenger safety (Figure $4,5)$.
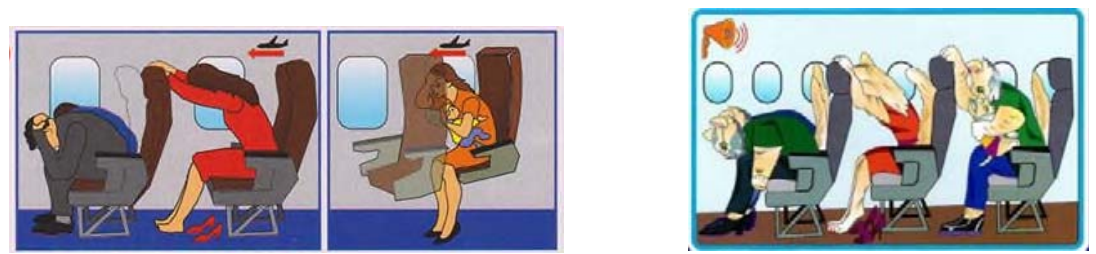

$\mathrm{a}$

b

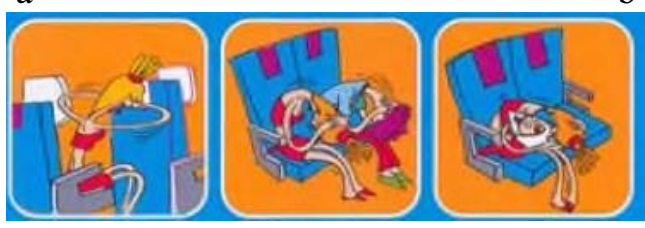

c

Fig. 4. Image of the passenger's pose during an emergency landing: a - Red Wings, b- Azimuth.aero, c-S7. 


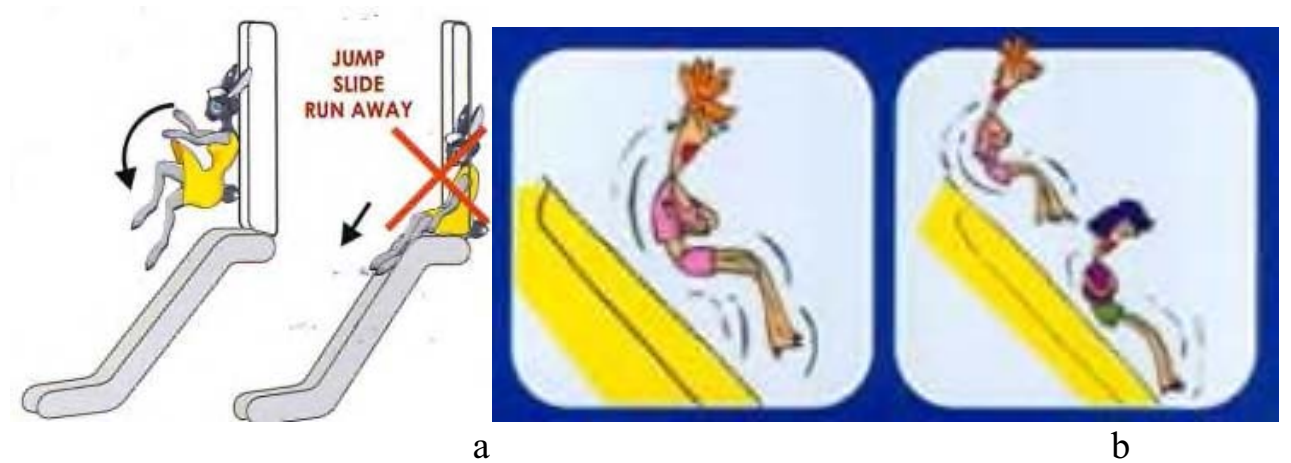

Fig. 5. Evacuation by ladder: a - Azimuth.aero, b - S7.

So, the images in figures 3-5 are of a didactic nature and are intended to perform a training function-to demonstrate samples of correct behavior of passengers and / or a sequence of actions that ensure safety. All drawings of the instructions of various airlines strictly follow the image of the standard required number of operations or showing representatives of different groups of passengers according to the criterion of gender and the presence of children in their hands.

However, it can be argued that only Aeroflot and Red Wings show a serious attitude to these processes.

The style of didactic illustrations of these companies' sets passengers up for a serious mood, and the nonverbal communicative picture of behavior patterns focuses on a thorough acquaintance with its content. Didactic illustrations by Azimuth.aero and S7, on the other hand, present serious, vital content as a game, farce, joke, or even mockery. Illustrations of this kind, of course, attract the eyes of passengers, but do not set up the need to comply with the prescribed rules of behavior in an extreme situation.

\section{Conclusion}

According to the study, Russian air carriers strictly comply with the regulations of the ICAO-International Civil Aviation Organization and develop their own instructions based on them. The current situation in the field of civil air transportation is characterized by the presence of competition associated with the struggle for passengers. Newly established carriers, or carriers that have re-branded and adopted new marketing strategies, are using every opportunity to attract passengers' attention through new approaches to the visualization of mandatory information. In general, airlines are abandoning direct advertising, but today many other methods and channels are used to attract passengers, as well as increase their loyalty.

The regulatory documents of the International and national organizations of civil air carriers in the texts of the instructions are formally followed, since they reflect the leading regulatory positions in the field of security. The prohibition on the use of advertising in passenger instructions is also formally respected, but the newly created airlines are using a hidden advertising strategy and serving serious content in an ironic and playful way, using mechanisms of hidden analogy. The image of a flight attendant is presented in the form of a caring hare, passengers - in the form of coquettish foxes (Azimuth.aero); flight attendants and passengers are presented in glamorous images on the instructions of the S7 airline, which reduces the focus of passengers on learning the essence of the instructions. These approaches implement the postmodern principle "Anything goes!", Which, of course, 
reflects the ideological pathos of the era, but does not set passengers up for a serious attitude to the information contained in the instructions not only useful, but also vital.

The developers of the instructions demonstrate excessive creativity in complying with the requirements of clause 4.5.6., according to which the instructions should be interesting and attractive to the passenger.

\section{References}

1. Convention on International Civil Aviation

2. Global Aviation Safety Plan, 2020 - 2022

3. R. Bowyer, Ph. Gill, Objective verification of global in-flight icing forecasts using satellite observations: Verification of WAFS icing forecasts using satellite observations, Meteorological applications 26(4) (2019) 610-619 DOI: $10.1002 /$ met. 1788

4. D. Kelly, M. Efthymiou, An analysis of human factors in fifty controlled flight into terrain aviation accidents from 2007 to 2017, Journal of safety research 69, 155-165 (2019) DOI: 10.1016/j.jsr.2019.03.009

5. M. Ripepe, E. Marchetti, Infrasonic Early Warning System for Explosive Eruptions, Journal of Geophysical Research-Solid Earth 23 (11), 9570-9585 (2018) DOI: 10.1029/2018JB015561

6. S. Albersheim, M. Guffanti, The United States national volcanic ash operations plan for aviation, Natural Hazards 51(2), 275-285 (2009) DOI: $10.1007 / \mathrm{s} 11069-008-9247-1$

7. O. Fedotova, V. Latun, Illustration in the In-flight Magazines of the European Airlines: Expansion of the Outlook or Aggressive Advertising? Procedia Social and Behavioral Sciences 214, 871-875 (2015) DOI: 10.1016/j.sbspro.2015.11.743

8. C. Fernandez, Warehouses of a time in flight: Cultural magazines in the Hispanic modernity, ORBIS TERTIUS 20 (22), 123-125 (2015)

9. C. Manvichien, Vitality of Safety Factors: A Case Study of Thai Airways Passengers, Procedia Social and Behavioral Sciences 197, 2103-2109 (2015) DOI: 10.1016/j.sbspro.2015.07.330

10. L. Chittaro, C. Corbett, Safety knowledge transfer through mobile virtual reality: A study of aviation life preserver donning, Safety science 102, 159-168 (2018)DOI: $10.1016 /$ j.ssci.2017.10.012

11. Interaction Research Corporation

12. N. Cohn, Beyond speech balloons and thought bubbles: The integration of text and image, Semiotica 197, 35-63 (2013) DOI: 10.1515/sem-2013-0079

13. C. Rigaud, D. Karatzas, Adaptive Contour Classification of Comics Speech Balloons, Graphics recognition: current trends and challenges 8746, 53-62 (2014) DOI: 10.1007/978-3-662-44854-0_5 